цифровым обществом. В связи с этим, развивается социально-экономическая и социально-правовая государственная поддержка молодежи государств членов ЕАЭС. Более того, создание Экспертного совета молодежи соответствует целям Договора о ЕАЭС от 29 мая 2014 г., в частности в процессах устранения и несоздания препятствий на рынках государств - членов ЕАЭС, обеспечения связанности цифровых инфраструктур ${ }^{4}$.

\section{Список источников:}

1.Решение Высшего Евразийского экономического совета от 11 октября 2017 г. № 12 “Об Основных направлениях реализации цифровой повестки Евразийского экономического союза до 2025 года".

2.Данные ЕЭК, Социально-демографические индикаторы статистика ЕАЭС, январь - июнь 2019 года.

URL:

http://www.eurasiancommission.org/ru/act/integr_i_m
akroec/dep_stat/econstat/Documents/Bulletin_SDI/SD I\%202019_06.pdf (Дата обращения: 20.10.2019).

3.Экспресс-информация от 04 марта 2019 г., Статистика Евразийского экономического союза, «О безработице в Евразийском экономическом союзе».

4.Социально-экономическая статистика

ЕАЭС, $2019 . \quad$ URL: http://www.eurasiancommission.org/ru/act/integr_i_m akroec/dep_stat/union_stat/Pages/default.aspx (Дата обращения: 21.10.2019).

5.Количественный анализ: евразийской интеграции: проекты Центра интеграционных исследований ЕАБР, Евразийский Банк развития, 01.06.2018.

6.Данные ЕЭК, Социально-экономическая статистика, раздел «Образование», 2019 год. URL: http://www.eurasiancommission.org/ru/act/integr_i_m akroec/dep_stat/union_stat/Pages/default.aspx (Дата обращения: 10.10.2019).

ОЦЕНКА И АНАЛИЗ РИСКА ИНВЕСТИЦИОННЫХ ВЛОЖЕНИЙ ПРИ РАЗРАБОТКЕ ГАЗОВЫХ МЕСТОРОЖДЕНИЙ

DOI: $10.31618 /$ ESU.2413-9335.2020.5.71.605

Гасумов Э.Р.

Азербайджанский Университет нефти и промышленности, кандидат экономических наук, старший преподаватель

\title{
EVALUATION \& ANALYSIS OF RISKS WHEN INVESTING IN THE DEVELOPMENT OF GAS FIELDS
}

Gasumov E.R. Azerbaijan State University of Oil and Industry, candidate of Economic Sciences, Senior Lecturer

\section{АННОТАЦИЯ}

В статье рассмотрены возможные риски при инвестировании разработки газовых месторождений, классификация (сфера и стадия проявления, причины возникновения, последствия проявления) и виды рисков, особенности рисков при реализации инвестиционных проектов и их оценки, метода управления рисками.

\section{ANNOTATION}

The article discusses the possible risks when investing in the development of gas fields, classification (sphere and stage of manifestation, causes of appearance, consequences of manifestation) and the types of risks, features of risks in the implementation of investment projects and their assessment, risk management techniques.

Ключевые слова: инвестиция, разработка, газовые месторождения, риски, проекты, эффективность, оценка, методы управления и др.

Keywords: investment, development, oil and gas production, risks, projects, efficiency, evaluation, management methods \& etc.

Газовые месторождения представляют собой сложные природные комплексы, главным признаком которых является наличие скопления углеводородов в пористом пласте-коллекторе, ограниченном непроницаемыми покрышкой и основанием. Размеры скопления, состав, фазовое состояние и реологические свойства углеводородной смеси характеризуются большим разнообразием. Весьма разнообразны также коллекторские свойства, глубины залегания, толщины и начальные термобарические параметры вмещающих углеводороды пород. Если учесть еще и широту спектра природно-климатических условий в зонах расположения месторождений, то очевидно, сколь многообразны проблемы, решение которых необходимо при проектировании разработки залежей и отборе запасов природного газа [1-3].

Разработка газовых месторождений - комплекс работ по извлечению природного газа из пластаколлектора. Под системой разработка газовых месторождений понимают размещение на площади газоносности и структуре необходимого числа эксплуатационных наблюдательны и

\footnotetext{
${ }^{4}$ Цифровая повестка ЕАЭС
} 
пьезометрических скважин и соблюдением порядка ввода их в эксплуатацию и поддержанием допустимых технологических режимов эксплуатации скважин. Добываемый природный газ на поверхности подвергается промысловой обработке. Для этого применяется соответствующая система обустройства газового промысла и эксплуатационных расходов, себестоимостью добычи газа и др. При этом применение инновационных методов является важным разделом проекта разработка газовых месторождений.

Инновационные методы повышения эффективности разработки газовых месторождений являются комплексом принципиальных технологических решений, направленных на улучшенную выработку запасов газа по сравнению с традиционными методами. Отличительной чертой этих методов является необходимость существенных научно-исследовательских проработок в каждом конкретном случае, а также их затратный характер, повышенный технологический и экономический риск. Обоснование и осуществление инвестиционных вложений при разработке газовых месторождений c наличием инновационного фактора является важным и рискованным процессом $[4,5]$.

Вклад инновационного фактора в газовой отрасли измеряется показателями инвестиционных составляющих, отражающих долю инновационной добычи и инновационной прибыли в их общем объеме по газодобывающему предприятию в целом. При этом основным показателем эффективности применения инноваций в газовой отрасли является достижение максимального результата (прироста рентабельных в данных экономических условиях запасов и добычи углеводородного сырья) при сохранении необходимого соотношения между приростом и отбором углеводородов с возможными ограничениями по основным видам ресурсов: финансовым, материальным, трудовым, энергетическим и т.д.

Реализация инновационных подходов в проектах при разработке газовых месторождений всегда сопровождается определенными рисками, это обусловлено особенностями месторождений, как наличием комплекса сложных инженерных сооружений. В связи чем, при планировании фактор риска инвестиционных вложений должен быть учтен и прогнозирован $[6,7]$.

Расчет риска осуществляется, как правило, на стадии проектирования разработки месторождений с использованием методологии вероятностного анализа безопасности. Расчетные методы позволяют оценить риск применительно к конкретному объекту, а не группе однотипных объектов.

В настоящее время наиболее эффективным является комплексный подход к анализу рисков. С одной стороны, он позволяет получать более полное представление о возможных результатах реализации проекта, то есть обо всех позитивных и негативных факторах для инвестора, a, с другой стороны, делает возможным широкое применение математических методов (в особенности вероятностно-статистических) для анализа рисков [8].

В условиях действия разнообразных внешних и внутренних факторов риска могут использоваться различные способы снижения риска, воздействующие на те или иные стороны деятельности компании. Методы компенсации рисков связаны с созданием механизмов предупреждения опасности. Они более трудоемки и требуют обширной предварительной аналитической работы для их эффективного применения.

Планирование

производственной деятельности газодобывающих компаний осуществляется для обеспечения проектных уровней добычи газа и жидких углеводородов, обеспечения безопасной эксплуатации фонда скважин на месторождениях. Одним из основных направлений производственной деятельности газодобывающих компаний в заключительный период разработки месторождения является поддержание проектных уровней добычи газа.

Проектные инвестиционные решения могут приниматься в различных условиях, которые называются средой принятия решений. Обычно выделяют три возможных среды: определенности (детерминированности), риска (вероятностной определенности) и неопределенности. Среда определенности характеризуется известными ведущими состояниями системы или, другими словами, известными возможными исходами реализации решения.

Риск определяется как опасность, возможность убытка или ущерба. Следовательно, риск относится к возможности наступления какого - либо неблагоприятного события. Под риском принято понимать вероятность возможных потерь части ресурсов, недополучения доходов, появления дополнительных расходов по сравнению с вариантом, предусмотренным проектом, или дисперсию вокруг предполагаемого результата. Средой риска в этом случае является ситуация, когда известны возможные исходы осуществления проекта и вероятности их появления. Среда неопределенности соответствует такой ситуации, когда известны только возможные исходы реализации проекта и неизвестны вероятности этих исходов.

Газовая промышленность как система характеризуется рядом специфических особенностей, отличающих ее от других отраслей материального производства. Как уже отмечалось, наиболее существенными из них с точки зрения анализа эффективности инвестиционных проектов и оценки риска являются большая зависимость показателей и критериев эффективности затрат от природных условий, от уровня использования разведанных и извлекаемых ресурсов углеводородов; динамический характер (изменчивость во времени) природных факторов; 
вероятностный характер большинства техникоэкономических показателей разработки нефтяных и газовых месторождений; изменение воспроизводственной структуры капиталовложений в масштабе отрасли в сторону увеличения их доли, направляемой на компенсацию падения добычи на старых месторождениях; большая продолжительность реализации нефтяных и газовых проектов; высокая капиталоемкость нефтедобычи, необходимость осуществления крупных инвестиций, длительный период возмещения начального капитала.

Эти особенности газовой промышленности оказывают влияние и на формирование системы проектных рисков. Инвестиционным проектам в этих отраслях присуще все виды рисков: социально-политические, экологические, правовые, экономические, технологические, производственные. Кроме этих рисков специфическими для нефтяной отрасли являются риск неоткрытия месторождения; риск, связанный с неточным определением геолого-промысловых характеристик объекта разработки (объема геологических запасов, динамики добычи углеводородов и т. д.); риск, связанный с завершением проекта; риск, связанный с условиями рынка сбыта нефти, газа, нефтепродуктов; риск, обусловленный качествами участников проекта; риск, вызванный повышенной вероятностью возникновения форс-мажорных ситуаций.

Классификация рисков, возникающих при реализации инвестиционных проектов разработки газовых месторождений приведена в таблице 1.

Таблица 1.

Классификация рисков при реализации инвестиционных проектов разработки газовых месторождений

\begin{tabular}{|c|c|}
\hline Признак классификации & Виды рисков \\
\hline А. Общие & \\
\hline Сфера проявления & Политический, социальный, производственный, \\
коммерческий, финансовый, экологический и др.. \\
Функциональный, денежный, инфляционный, риск \\
ликвидности и др.
\end{tabular}

Основными причинами рисков, возникающих при реализации инвестиционных проектов разработки месторождений, являются: распределение отдачи от проекта во времени; разброс значений каждой переменной, влияющей на величину критериев эффективности; значительные расходы, связанные со сбором дополнительной информации.

Bce участники проекта (инвестор, недропользователь, подрядные организации, проектные организации и др.) заинтересованы в том, чтобы снизить вероятность принятия неудачного (неэффективного) решения, избежать полного провала проекта или хотя бы значительных убытков. Для этого участники проекта вынуждены учитывать все возможные последствия реализации проекта в быстро меняющейся рыночной среде.

Таким образом, назначение анализа риска заключается в том, чтобы дать потенциальным партнерам необходимую информацию для принятия решений о целесообразности участия в проекте и предусмотреть меры по защите от возможных финансовых потерь. Для снижения вероятности принятия неэффективного решения необходимо до проведения анализа риска определить классификационные признаки проектных решений; оценить в какой сфере экономики (позитивной или нормативной) относится решение; уметь решать проблему (готовить и принимать решение) поэтапно.

Позитивный анализ, как уже говорилось, предполагает объяснение и прогнозирование явлений в экономике, а нормативный отвечает на вопрос, как должно быть. С помощью нормативного анализа готовятся и принимаются, в основном, политические решения (введение или отмена налогов, пошлин, изменение минимального уровня заработной платы и т. д.).

Как показывает практика и в своих построениях учитывает экономическая теория, лица, принимающие решения об инвестициях, могут быть расположены к риску, не расположены к риску или безразличны к нему. Как опять же показывает практика, большинство инвесторов не склонны к риску, что подтверждается их стремлением застраховаться от рискованных ситуаций. 
Главная задача качественного анализ определить факторы риска, этапы и работы, при выполнении которых она возникает, установить потенциальные области риска, после чего идентифицировать все возможные риски. В практике управления проектами существует несколько способов снижения риска.

Риск проекта на этапе его реализации можно уменьшить, предусмотрев диверсификацию распределение усилий предприятия между видами деятельности, результаты которых непосредственно не связаны между собой.

Принимая решение об инвестициях в какойлибо проект, инвестор должен рассматривать проект не изолированно, а во взаимосвязи с другими проектами и с уже имеющимися видами деятельности предприятия. В целях снижения риска желательно выбирать производство таких товаров или услуг, спрос на которые изменяется в противоположных направлениях.

Для измерения взаимосвязи между какимилибо видами деятельности предприятия используется показатель корреляции. Диверсификация с отрицательной корреляцией, в основном, несколько уменьшает совокупную отдачу от проектов, но в тоже время сокращает риск резкого уменьшения доходов.

Распределение риска между участниками проекта также является одним из способов его снижения. Обычная практика распределения риска заключается в том, чтобы сделать ответственным за конкретный вид риска того участника проекта, который в состоянии лучше всех остальных рассчитывать и контролировать этот риск.

Проблема распределения риска носит двойственный характер, обусловленный участием в инвестиционном проекте, по меньшей мере двух участников заказчика и исполнителя (подрядчика). Заказчик стремится по возможности уменьшить стоимость контракта. С другой стороны исполнитель работ при формировании портфеля заказов стремится к получению приемлемой для него массы прибыли.

Большинству крупных проектов в нефтегазовой промышленности, как показывает практика, свойственны задержки в их реализации, что может привести к такому увеличению стоимости работ, которая превысит первоначальную стоимость проекта. Выход из такой ситуации заключается в том, что к участию в проекте должна быть привлечена страховая компания. Страхование риска есть по существу передача определенных рисков страховой компании.

Уменьшить уровень риска проекта в ряде случаев можно путем приобретения дополнительной информации, позволяющей уточнить некоторые параметры проекта, повысить уровень надежности и достоверности исходной информации и снизить вероятность принятия неэффективного решения.

Приобретение дополнительной информации проведения эксперимента целесообразно, если стоимость информации (эксперимента) не превышает минимального среднего риска.

Последним из наиболее распространенных способов снижения риска проекта является резервирование средств на покрытие непредвиденных расходов. Этот способ предусматривает установление соотношения между потенциальными рисками, влияющими на стоимость проекта, и размером расходов, необходимых для преодоления нарушений в ходе его реализации.

При определении суммы резерва необходимо учитывать точность первоначальной оценки стоимости проекта и его элементов в зависимости от этапа проекта, на котором проводилась эта оценка. Возможны следующие подходы формирование резерва:

- при первом подходе резерв делится на две части: на общий и специальный;

- второй подход к созданию структуры резерва предполагает определение непредвиденных расходов по видам затрат: основные и вспомогательные материалы, оборудование, заработная плата и т.д.

В общем случае резерв не должен использоваться для компенсации потерь, понесенных вследствие неудовлетворенной работы участников проекта.

Стратегическим направлением инвестиционной деятельности нефтедобывающей организации является реализация проектов, обеспечивающих расширение ресурсной базы и повышение добычи углеводородного сырья.

В настоящее время наиболее эффективным является комплексный подход к анализу рисков. С одной стороны, такой подход позволяет получать более полное представление о возможных результатах реализации проекта, т.е. обо всех позитивных и негативных неожиданностях, ожидающих инвестора, а с другой стороны, делает возможным широкое применение математических методов (в особенности вероятностностатистических) для анализа рисков [8]..

При выборе конкретного метода управления рисками риск-менеджер должен исходить из следующих принципов:

- нельзя рисковать больше, чем это может позволить собственный капитал;

- нельзя рисковать многим ради малого;

- следует предугадывать последствия риска.

Необходимо перейти в управлении риском к интегрированному подходу, в котором средства и методы совместно используются на всем предприятии, а в управлении компанией есть хорошо продуманная стратегия. Интегрированный подход - это активная позиция, так как подразумевает предвидение, а не пассивную реакцию на риск, такой подход предоставляет больше возможностей и ограничивает опасности.

\section{Список использованной литературы}

Гасумов Э.Р. Управление инновациями при выполнении геолого-технических мероприятий по 
фонду скважин. // Научно-экономический журнал «Проблемы экономики и управления нефтегазовым комплексом», №7, Москва, -2011, с. 26-30.

Гасумов Э.Р., Толстых Н.Л. Применение инновационных решений при проектировании объектов нефтегазодобычи. // Научно-технический журнал «Нефть. Газ. Новации», № 9, - Самара, 2011, C. 6-8.

Гасумов Э.Р. Реализация инновационных подходов при разработке газовых и газоконденсатных месторождений. // Научнотехнический и производственный журнал - «Наука и ТЭК», Тюмень.: № 6, ноябрь 2011, С. 27-29.

Гасумов Э.Р. Инновационная деятельность в нефтегазодобыче. // Журнал научных публикаций. // Актуальные проблемы гуманитарных и естественных наук. М.: №11(34) ноябрь 2011. С.8790.

Внедрение инноваций при освоении месторождений углеводородов. /Гасумов Э.Р.
//Научный журнал «Естественные и технические науки». -М.: -2019. - №6(132). -C. 100-105.

Применение инновационных решений при проектировании объектов нефтегазодобычи. /Гасумов Р.А., Гасумов Э.Р. //Научный журнал «Территория «Нефтегаз». -М.: -2017. -№ 4. -С.7883.

Инновационные решения для обеспечения проектного уровня добычи газа. /Гасумов Р.А., Гасумов Э.Р. //Научно-технический журнал «Нефтепромысловое дело». -М.: ВНИИОЭНГ. 2016. - № 10. - С. 20-27.

Гасумов Э.Р. Управления и оценки рисков внедрения инноваций при проведении ГТМ по фонду газовых скважин. //Булатовские чтения: материалы II Международной научнопрактической конференции (31 марта 2019 г.) в 7 т. - Краснодар: -2019. Т. 2. Ч. 1. С.163-171.

УДК 332.6

ИНФОРМАЦИОНОЕ ОБЕСПЕЧЕНИЕ УПРАВЛЕНИЯ ЗЕМЕЛЬНЫМИ РЕСУРСАМИ DOI: $\underline{10.31618 / \text { ESU.2413-9335.2020.5.71.606 }}$

Жданова Руслана Владимировна кандидат экономических наук, доцент, дочент кафедры землепользования и кадастров, ФГБОУ ВО «Государственный университет по землеустройству» (105064, Россия, г. Москва, ул. Казакова, д. 15),

ORCID: http://orcid.org/0000-0002-9069-1559,

\section{АННОТАЦИЯ}

В данной статье рассмотрено информационное обеспечение управления земельными ресурсами. Показана общие принципы управления, виды информации по назначению в процессе управления, а также причины обусловливающие необходимость информационного обеспечения в области управления земельными ресурсами. Из проведенных исследований были сделаны выводы.

Ключевые слова: информационное обеспечение, управление земельными ресурсами, вид информации, территория, объект недвижимости, земельный участок.

Для рационального использования земель каждый объект недвижимости имеет свои особенности, соответственно для рационального использования земель необходимо эффективное и научно обоснованное управление процессами, в которые вовлечены участники земельных отношений. Главной информационной основой управления земельными ресурсами, конечно, является Единый государственный реестр недвижимости, сведения которого дают возможность принимать как оперативные, так и качественные управленческие решения в области реализации земельной политики административно территориального образования.

Также важно выделить то, что самостоятельно определить перспективу развития муниципального образования, обеспечить целенаправленное выполнение поставленных задач не могут по отдельности муниципальные образования, государство, предприятия и организации. Только скоординированное взаимодействие всех участников обеспечивает продуманное и согласованное развитие территории.

Далее рассмотрим на рисунке 1 общие принципы управления земельными ресурсами. 